\title{
Non-pathogenic Staphylococcus strains augmented the maize growth through oxidative stress management and nutrient supply under induced salt stress
}

\author{
Muhammad Shahid $^{1}$ (D) $\cdot$ Temoor Ahmed $^{1} \cdot$ Muhammad Noman $^{1} \cdot$ Muhammad Tariq Javed $^{2}$. \\ Muhammad Rizwan Javed ${ }^{1}$. Muhammad Tahir ${ }^{3}$. Shahid Masood Shah ${ }^{4}$
}

Received: 14 November 2018 / Accepted: 13 March 2019/Published online: 23 March 2019

(C) Università degli studi di Milano 2019

\begin{abstract}
Purpose The present study was conducted to elucidate the role of phytobeneficial bacteria to control the cellular oxidative damage in maize (Zea mays L.) plants caused by salinity.

Methods Bacteria were isolated from the rhizosphere of kallar grass (Leptochloa fusca L.) through serial dilution method and taxonomically identified on the basis of their 16S ribosomal RNA gene sequencing. In vitro phosphate solubilization, indole-3acetic acid (IAA) synthesis, and 1-aminocyclopropane-1-carboxylic acid (ACC) deaminase activity were evaluated by solubilization index measurement, colorimetric method, and turbidity assay, respectively. In the pot experiment, the impact of single and mixed inoculation of these strains at four levels $(0,50,100$, and $200 \mathrm{mM})$ of salt stress was evaluated in terms of growth and physiological response of maize plants to salinity.

Results The bacterial strains (STN-1, STN-5, and STN-14) were taxonomically classified as Staphylococcus spp. At 5\% NaCl level, the strains demonstrated substantial potential for phosphate solubilization, ACC deaminase activity, and IAA production both with and without tryptophan. The inoculation of strains STN-1, STN-5, and mixed inoculation resulted in substantial growth improvement of maize plants along with increased antioxidant enzyme activity and decreased levels of reactive oxygen species. In addition, single inoculation of STN-1 and STN-5 along with mixed inoculation augmented the uptake of N, $\mathrm{P}, \mathrm{K}$, and $\mathrm{Ca}{ }^{+2}$ and reduced $\mathrm{Na}^{+}$uptake.

Conclusion Current results demonstrated that the strains STN-1 and STN-5 modulated stress-responsive mechanisms and regulated ion balance in induced salinity to promote maize growth.
\end{abstract}

Keywords Antioxidants $\cdot$ Indole-3-acetic acid $\cdot$ Maize $\cdot$ Phosphate solubilization $\cdot$ Phytobeneficial bacteria $\cdot$ Salinity tolerance

Electronic supplementary material The online version of this article (https://doi.org/10.1007/s13213-019-01464-9) contains supplementary material, which is available to authorized users.

Muhammad Shahid

mshahid@gcuf.edu.pk

1 Department of Bioinformatics and Biotechnology, Government College University, Faisalabad 38000, Pakistan

2 Department of Botany, Government College University, Faisalabad 38000, Pakistan

3 Department of Environmental Sciences, COMSATS University, Vehari Campus, Vehari, Pakistan

4 Department of Environmental Sciences, COMSATS University Islamabad, Abbottabad Campus, Abbottabad, Pakistan

\section{Introduction}

Salinity is a worldwide issue with devastating impacts on soil health and crop production (Shahbaz and Ashraf 2013). In Pakistan, a huge area of arable land (6.5 million ha) is saline and this situation is becoming more alarming with the diminishing water resources. Moreover, Pakistan is located in the ecological zone where rates of evapotranspiration are high causing the salinity problem (Zafar et al. 2016). Salinity causes ion toxicity in plants due to the increased concentration of $\mathrm{Na}^{+}$and $\mathrm{Cl}^{-}$in the root zone. Under such conditions, plants are subjected to cellular oxidative stress which is harmful for its survival and sustainability (Mayak et al. 2004). Such stressful conditions initiate the cellular ion imbalance and synthesis of harmful molecules in plants 
(Cheng et al. 2012). Under abiotic stress, the ethylene concentration is strictly regulated by rhizospheric bacteria in most plants to facilitate their growth (Panda et al. 2009; Shrivastava and Kumar 2015).

Plant growth-promoting rhizobacteria (PGPR) exist in the root zone and are assets for plants growing under unfavorable conditions. The plants are benefited by PGPR in terms of nutrient acquisition from soil, production of growth hormone and control of many pathogens (Babalola 2010; Heydarian et al. 2016). Both direct and indirect mechanisms are involved in PGPR-mediated nourishment of plants (Compant et al. 2005). Fixation of atmospheric nitrogen, solubilization of inorganic phosphates, and production of phytohormones are the direct mechanisms. On the other hand, many plant pathogens are indirectly controlled by PGPR by antibiosis and hydrolytic enzymes (Dobbelaere et al. 2003; Kumar et al. 2015). Under normal and stressed conditions, several documentary evidences confirm the better physiological and growth responses of diverse plant species to phytobeneficial bacteria (Kashyap et al. 2017; Meena et al. 2017)

The PGPR inoculation either on seeds or plants helps to ameliorate the salinity stress consequences due to the activation of several signaling pathways (Shukla et al. 2012). Salt-tolerant PGPR strains support the growth of plants by mitigating the cell oxidative damage and increasing uptake of nutrient ions (Akram et al. 2016; Shahid et al. 2018). Isolation of some members of genus Staphylococcus has been carried out from various environments and categorized as potential salt-tolerant PGPR with ability to relieve plants from antioxidative damage (Roohi et al. 2012). The PGPR also support plant growth under stress conditions by selection and regulation of $\mathrm{Na}^{+}, \mathrm{K}^{+}$, and $\mathrm{Ca}^{2+}$ ions (Hamdia et al. 2004). Moreover, many halotolerant PGPR species have been isolated from extreme environments and halophytes including kallar grass in order to harness their benefits after inoculation with non-halophytic plants (Akram et al. 2016; Etesami and Beattie 2018). Kallar grass, being a halophyte, may be a rich source of halotolerant PGPR with abiotic stress amelioration potential. Thus, plants inoculated with such salt-tolerant PGPR species demonstrated an enhanced osmotic adjustment and a moderate ethylene level due to the bacterial synthesis of 1-aminocyclopropane-1-carboxylate (ACC) deaminase (Dimkpa et al. 2009). In several microorganisms, indole-3-acetic acid (IAA) also serves as a signaling molecule and helps in abiotic stress tolerance (Spaepen and Vanderleyden 2011). The restricted nutrition and oxidative damage consequences in saline soil harshly influence the plant biomass including maize, which is the most important cereal crop cultivated extensively all over the world (Akram et al. 2016). It is rich in nutrition and a source of food for humans, feed for animals, and raw material for industrial purposes.

Based on the literature review, it was hypothesized that salt-tolerant bacteria have physiological implications in terms of relieving plants from oxidative damage and supporting plant growth by nutrient uptake. The current research was, therefore, planned to assess the capability of three salt-tolerant PGPR strains, isolated from kallar grass, to sustain maize growth by oxidative damage repair and ion regulation under induced saline conditions. The elucidation of the underlying mechanisms responsible for PGPR-mediated alterations in plant growth under salt stress was also in scope of the current work.

\section{Materials and methods}

\section{Isolation of bacteria and soil analysis}

The samples from Kallar grass (Leptochloa fusca (L.) Kunth) rhizospheres were collected from agricultural fields near Dalowal Sammundri road $\left(31.3032^{\circ} \mathrm{N}, 73.0265^{\circ} \mathrm{E}\right)$, district Faisalabad, Punjab, Pakistan at maturity stage. The roots with adhering soil were cut with a sterilized knife and weighed $(1 \mathrm{~g})$ with electronic balance for isolation of salt-tolerant bacteria through serial dilution method (Somasegaran and Hoben 1994). The test tubes containing $9 \mathrm{~mL}$ of sterilized saline solution $(0.85 \% w / v \mathrm{NaCl})$ were added with $1 \mathrm{~g}$ rhizosphere sample. One milliliter from each tube was transferred to next tube containing $9 \mathrm{~mL}$ saline solution. The mixing of suspension was performed with the help of vortex. The $10^{-4}$ and $10^{-6}$ dilutions were poured $(100 \mu \mathrm{L})$ onto the nutrient agar plates amended with $5 \%(w / v) \mathrm{NaCl}$. These plates were incubated at $28 \pm 2{ }^{\circ} \mathrm{C}$ for $48 \mathrm{~h}$. The isolates were repeatedly streaked for maximum purity. The purified isolates were stored in $20 \%(\mathrm{v} /$ v) glycerol at $-80^{\circ} \mathrm{C}$. Out of the total of 21 purified isolates, only three isolates (STN-1, STN-5, and STN-14) were selected based on substantial in vitro potential for phosphate solubilization, IAA potential, and ACC deaminase activity, whereas the remaining isolates were not included in further experiments. The physico-chemical analysis of sampled soils was carried out commercially at Ayub Agricultural Research Institute (AARI), Faisalabad, Pakistan.

\section{Determination of plant growth-promoting characteristics of bacterial strains}

\section{Phosphate solubilization}

Phosphate solubilization was estimated by measuring the solubilization index (SI) of halozones formed on Pikovskaya's 
agar medium amended with 5\% (w/v) NaCl (Pikovskaya 1948) and containing tricalcium phosphate as inorganic phosphate source. Spot inoculation of Petri plates was accomplished followed by incubation at $28 \pm 2{ }^{\circ} \mathrm{C}$ for 7 days. The SI was measured by the following formula.

$\mathrm{SI}=$ Colony diameter + Zone diameter/Colony diameter

\section{1-Aminocycloproane-1-carboxylic acid deaminase activity}

The ability of the isolates to use ACC ( $3 \mu \mathrm{L}, 0.5 \mathrm{M})$ as sole nitrogen source was determined by measuring the amount of $\alpha$-ketobutyrate produced after the catabolism of ACC in DF salt minimal broth amended with 5\% $(w / v) \mathrm{NaCl}$. The tubes were kept at $28 \pm 2{ }^{\circ} \mathrm{C}$ for $48 \mathrm{~h}$. The absorbance of inoculated (inoculated with STN-1, STN-5, or STN-14) tubes containing ACC was compared with tubes containing ACC without inoculation and inoculated tubes without ACC (Penrose and Glick 2003). Standard curve of $\alpha$-ketobutyrate ranging between 0.1 and $1.0 \mu \mathrm{M}$ was drawn to calculate $\alpha$ ketobutyrate produced by the isolates. Bradford method (Bradford 1976) was employed to calculate the protein concentration in cell extracts.

\section{Auxin synthesis}

Auxin production of the isolates was estimated by the method described by Gordon and Weber (1951). The cultures were grown in salt-amended $(5 \% \mathrm{w} / \mathrm{v})$ LB-broth medium supplemented with tryptophan $\left(100 \mathrm{mg} \mathrm{L}^{-1}\right)$. The isolates were cultured by shaking $(150 \mathrm{rpm})$ at $28 \pm 2{ }^{\circ} \mathrm{C}$ for $48 \mathrm{~h}$ followed by harvesting at $13,000 \mathrm{~g}$ to collect the supernatant. One part of supernatant was mixed in two parts of Salkowisk's reagent $\left(2 \% 0.5 \mathrm{FeCl}_{3}\right.$ in $35 \% \mathrm{HClO}_{4}$ solution) in test tubes. The pink color, developed after the incubation for $30 \mathrm{~min}$ in the dark, was quantified by spectrophotometer. The IAA standards were run on spectrophotometer and standard curve was obtained to compare the results.

\section{Taxonomic identification}

Genomic DNA of the isolates STN-1, STN-5, and STN-14 was isolated by the CTAB method (Maniatis et al. 1982) and measured by the Nano Drop ${ }^{\mathrm{TM}}$ 2000/2000c (Thermo Fisher Scientific, Waltham, MA, USA). The DNA was used as a template to amplify the 16S rRNA gene using primer set fD1 (5' AGAGTTTGATCCTGGCTCAG 3') and rD1 (5' AAGGAGGTGATCCAGCC 3) (Weisburg et al. 1991). The amplicons were sent to Macrogen, South Korea for sequencing though Sanger method. The taxonomic identity of the strains was confirmed by BLASTn analysis and by constructing the neighbor-joining phylogenetic tree with type strains using MEGA 7.0 software package as described by Shahid et al. (2017). The clustering constancy of the tree was estimated by bootstrap study of 1000 data sets. The sequence data of STN-1, STN-5, and STN-14 were deposited in GenBank under the accession numbers MH152329, MH152330, and MH152331, respectively.

\section{Gelatinase and hemolysis activity}

Standard procedures described by Harrigan and McCance (1990) and Gerhardt et al. (1981) were used to investigate the gelatinase and hemolysis activities, respectively. Staphylococcus aureus ATCC 25923 was obtained from Chughtais Lahore Lab, Lahore and was used as positive control.

\section{Greenhouse experiment}

\section{Plant material, soil, and experimental design}

The clay loam soil with known physico-chemical properties (Shahid et al. 2018) was used to fill the pots. The surface sterilization of maize seeds (cv. FH-992) was carried out by rinsing with sodium hypochlorite $(5 \%$ $w / v$ ) for $10 \mathrm{~min}$ and five subsequent washings were given with $\mathrm{ddH}_{2} \mathrm{O}$. The inoculums were prepared by growing the strains STN-1, STN-5, and STN-14 up to

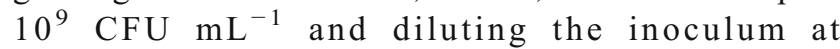
$10^{7} \mathrm{CFU} \mathrm{mL} \mathrm{mL}^{-1}$ with $\mathrm{ddH}_{2} \mathrm{O}$. The soil was either mixed with inoculum of STN-1, STN-5, STN-14, and mixed inoculum of these three strains at the rate of $7 \mathrm{~mL}$ $100 \mathrm{~g}^{-1}$ soil (inoculated soil) or with the same amount of $\mathrm{ddH}_{2} \mathrm{O}$ (non-inoculated soil). Moreover, the seeds were either dipped in the inoculum or in $\mathrm{ddH}_{2} \mathrm{O}$ for $20 \mathrm{~min}$. Both inoculated and non-inoculated seeds were sown in respective pots (five seeds per pot and $700 \mathrm{~g}$ soil in each pot). After the seedling development, the plants were thinned to three in each pot. Hoagland solution was applied as nutrition source for plants (Arnon and Hoagland 1940). The four $\mathrm{NaCl}$ levels, i.e., 0, 50, 100 , and $200 \mathrm{mM}$, were applied $(7 \mathrm{~mL}$ per $100 \mathrm{~g}$ soil $)$ with Hoagland solution twice; firstly, after seedling emergence, and secondly, after 15 days of planting. The whole experiment was conducted in greenhouse (with day/night temperature $25: 20{ }^{\circ} \mathrm{C}$, light/dark periods 16:8 h) under completely randomized design (CRD) with three replications for a period of 1 month.

\section{Measurement of growth parameters}

The plants were carefully uprooted and length $(\mathrm{cm})$ of root and shoot were measured with the help of a scale followed by the determination of fresh weight $(\mathrm{g})$ on 
electronic balance. The root and shoot samples were kept at $80{ }^{\circ} \mathrm{C}$ for $48 \mathrm{~h}$ in an oven for the measurement of dry weight.

\section{Measurement of physiological parameters}

\section{Lipid peroxidation and proline content}

The fresh shoots were sampled for the measurement of lipid peroxidation products by thiobarbituric acid (TBA) reaction (Heath and Packer 1968) and proline content by Bates et al. (1973). The shoot material was subjected to homogenization, centrifugation, and incubation steps as described by the above methods. Lipid peroxidation was estimated at $532 \mathrm{~nm}$ and proline content at $520 \mathrm{~nm}$ by UV-VIS spectrophotometer (Hitachi U-2910, Tokyo, Japan).

\section{$\mathrm{H}_{2} \mathrm{O}_{2}$ content and total phenolic contents}

A method described by Jana and Choudhuri (1982) was employed to measure the plant $\mathrm{H}_{2} \mathrm{O}_{2}$ content, while total phenolic contents were measured by the method described by Julkunen-Tiitto (1985). The centrifugation and incubations steps with homogenized samples were performed according to the above mentioned methods. Colorimetric measurements of $\mathrm{H}_{2} \mathrm{O}_{2}$ and phenolic contents were made at $410 \mathrm{~nm}$ and $750 \mathrm{~nm}$, respectively, by using a spectrophotometer unit mentioned in the above section.

\section{Catalase activity and peroxidase activity}

Catalase (CAT) and peroxidase (POD) activities were measured by method described by Aebi (1984) and Chance and Maehly (1955), respectively. Homogenization of fresh shoot samples was made in phosphate buffer $(50 \mathrm{mM} ; \mathrm{pH} 7.8)$ followed by spinning at $10,000 \mathrm{~g}$ for $10 \mathrm{~min}$ and absorbance was measured by using a spectrophotometer unit mentioned in the above section at $240 \mathrm{~nm}$ for catalase and $470 \mathrm{~nm}$ for peroxidase.

\section{Determination of nutrient elements}

For elemental analysis, plants were washed in $\mathrm{ddH}_{2} \mathrm{O}$ twice, dipped in $20 \mathrm{mM}$ EDTA for $3 \mathrm{~s}$, and washed again. The samples were oven dried for $24 \mathrm{~h}$ at $105^{\circ} \mathrm{C}$ followed by digestion using wet digestion method in $\mathrm{HNO}_{3} / \mathrm{HClO}_{4}(7: 3 v / v)$. The clear samples were mixed with distilled water up to $50 \mathrm{~mL}$ followed by elemental analysis using an atomic absorption spectrophotometer (Hitachi Model 7JO-8024, Tokyo, Japan) (Wolf 1982).

\section{Ionic concentration in plant dry matter}

Oven-dried plant samples were ground and $0.5 \mathrm{~g}$ of the samples were digested with a mixture $\mathrm{HNO}_{3} / \mathrm{HClO}_{4} / \mathrm{H}_{2} \mathrm{SO}_{4}$ $(8: 1: 1, v / v)$ at $150{ }^{\circ} \mathrm{C}$ for $45 \mathrm{~min}$, mixed with $2 \mathrm{M} \mathrm{HCl}$, and filtered with filter paper (Whatman no. 41). After the filtration, distilled water was added to make the volume $100 \mathrm{~mL}$. The ionic contents of $\mathrm{Na}^{+}, \mathrm{K}^{+}$, and $\mathrm{Ca}^{+2}$ were determined in the digested samples on an atomic absorption spectrophotometer (Hitachi Model 7JO-8024, Tokyo, Japan) (Ryan et al. 2007).

\section{Statistical analyses}

The data were analyzed by two-way analysis of variance using Statistix (version 8.1) software package (Steel et al. 1997). The means, composed of three replications, were compared using least significance difference (Fisher's LSD) at 95\% confidence level.

\section{Results}

\section{Soil analysis}

Both the bulk soils and kallar grass rhizosphere soil were found to be sandy loam. The soil samples were high in terms of $\mathrm{EC}$ and $\mathrm{pH}$, but low in organic matter contents. Both soils were poor in nutritional status and found deficient in total $\mathrm{N}$ and available $\mathrm{P}$ and $\mathrm{K}$ (Table 1).

\section{Physiological characterization and molecular identification}

The strains STN-1, STN-5, and STN-14 were taxonomically identified as Staphylococcus spp. on the basis of BLASTn and phylogenetic analysis of their 16S rRNA gene sequence analysis (Table 2, Fig. 1). In the phylogenetic tree, strains STN-5 and STN-14 placed themselves in a separate clade, while strain STN-1 clustered itself with Staphylococcus sciuri subsp. sciuri strain DSM

Table 1 Physico-chemical analysis of sampled soil

\begin{tabular}{lll}
\hline Soil properties & Bulk soil & Rhizospheric soil \\
\hline Textural class & Sandy loam & Sandy loam \\
$\mathrm{EC}\left(\mathrm{dS} \mathrm{m}^{-1}\right)$ & 6.98 & 7.11 \\
$\mathrm{pH}$ & 8.1 & 7.7 \\
Organic matter (\%) & 1.47 & 1.91 \\
Organic C $\left(\mathrm{g} \mathrm{kg}^{-1}\right)$ & 3.4 & 4.39 \\
Total N $\left(\mathrm{g} \mathrm{kg}^{-1}\right)$ & 0.38 & 0.55 \\
Available $\mathrm{P}\left(\mathrm{mg} \mathrm{kg}^{-1}\right)$ & 3.4 & 4.5 \\
Available K $\left(\mathrm{mg} \mathrm{kg}^{-1}\right)$ & 201 & 222 \\
\hline
\end{tabular}


Table 2 Physiological characterization and taxonomic identification of the strains

\begin{tabular}{|c|c|c|c|c|c|c|c|}
\hline Strain & $\begin{array}{l}\text { Closest GenBank } \\
\text { match }\end{array}$ & $\begin{array}{l}\text { Identity } \\
(\%)\end{array}$ & $\begin{array}{l}\text { Accession } \\
\text { number }\end{array}$ & $\begin{array}{l}\text { Solubilization } \\
\text { index }\end{array}$ & $\begin{array}{l}\text { IAA Trp }^{+} \\
\left(\mu \mathrm{g} \mathrm{mL}^{-1}\right)\end{array}$ & $\begin{array}{l}\text { IAA Trp }^{-} \\
\left(\mu \mathrm{g} \mathrm{mL}^{-1}\right)\end{array}$ & $\begin{array}{l}\alpha \text {-Ketobutyrate } \\
\left(\text { nmol mg }^{-1} \text { protein } \mathrm{h}^{-1}\right)\end{array}$ \\
\hline STN-1 & Staphylococcus sp. & 99 & MH152329 & $5.34 \pm 0.67$ & $20.34 \pm 4.11$ & $11.34 \pm 3.67$ & $456.72 \pm 33.07$ \\
\hline STN-5 & Staphylococcus sp. & 100 & MH152330 & $3.78 \pm 0.46$ & $22.78 \pm 5.35$ & $9.39 \pm 2.63$ & $666.11 \pm 43.69$ \\
\hline STN-14 & Staphylococcus sp. & 99 & MH152331 & $2.65 \pm 0.47$ & $9.65 \pm 3.87$ & $8.27+1.98$ & $437.24 \pm 31.67$ \\
\hline
\end{tabular}

$20345^{\mathrm{T}}$ (AJ421446), Staphylococcus sciuri subsp. rodentium (AB233332), and Staphylococcus sciuri subsp. carnaticus strain GTC 1227 (AB233331). The assigned accession numbers after the sequence submission to GenBank were MH152329, MH152330, and MH152331, respectively. The strains showed substantial potential for inorganic phosphate solubilization and highest solubilization index was measured in STN-1 $(5.34 \pm 0.67)$ followed by STN-5 $(3.78 \pm 0.46)$. The IAA synthesis was estimated to be high under tryptophan-amended culture conditions as compared to non-tryptophan added media. The
Staphylococcus strain STN-5 demonstrated highest IAA production ability both with and without tryptophan followed by Staphylococcus strain STN-1 (Table 2). The isolates STN-1, STN-5, and STN-14 produced $\alpha$ ketobutyrate representing their ACC deaminase activity. The maximum amount of $\alpha$-ketobutyrate $(666.11 \pm$ $43.69 \mathrm{nmol} \mathrm{mg}^{-1}$ protein $\mathrm{h}^{-1}$ ) is produced by isolate STN-5 followed by STN-1 (456.72 $\pm 33.07 \mathrm{nmol} \mathrm{mg}^{-1}$ protein $\mathrm{h}^{-1}$ ) in culture medium. In comparison to positive control, the strains STN-1, STN-5, and STN-14 were found negative for gelatinase and hemolysis activities.

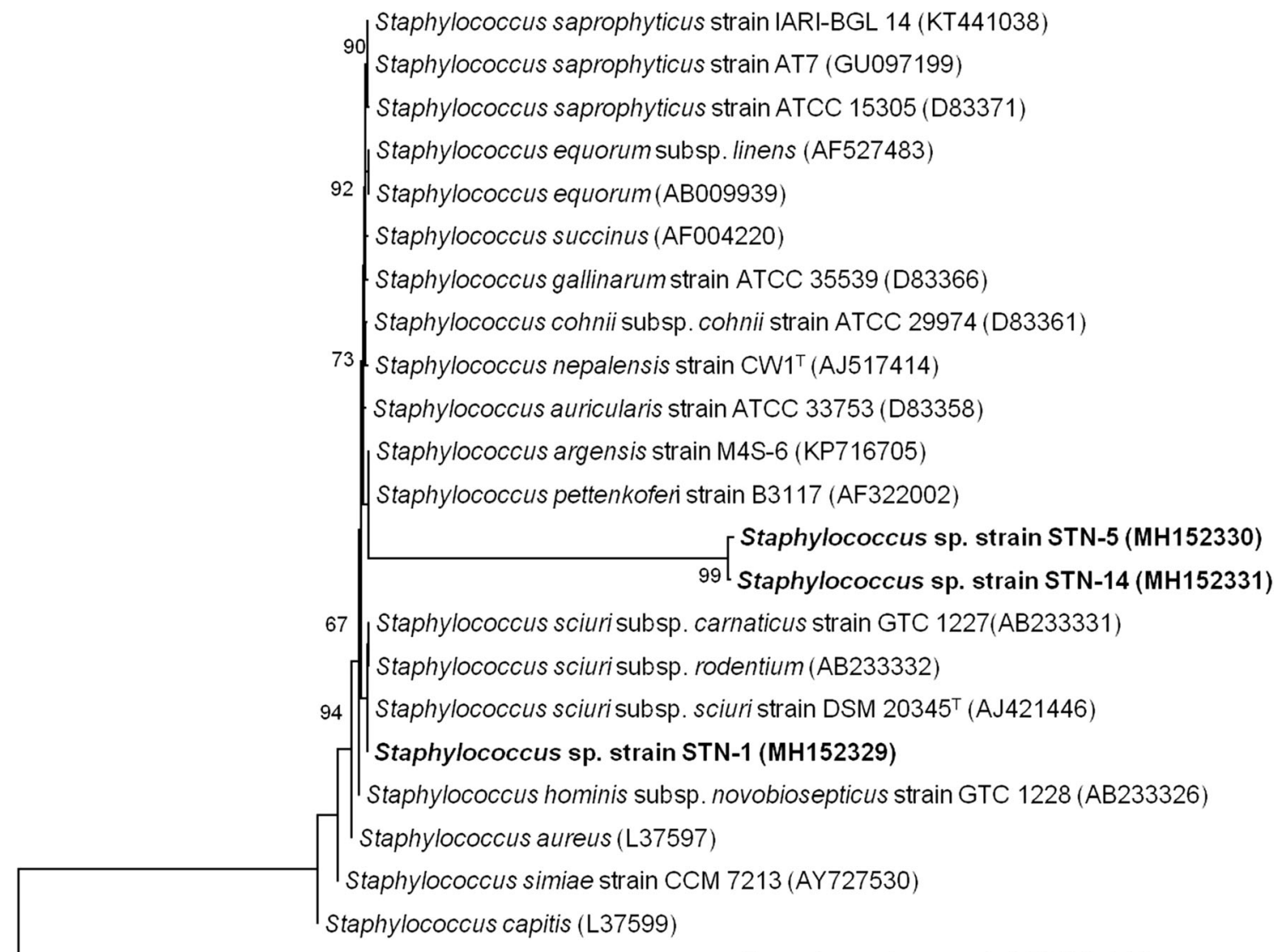

Enterobacterhormaechei (AM947046)

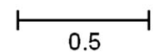

Fig. 1 Phylogenetic tree of Staphylococcus spp. (STN-1, STN-5, and STN-14) with the type strains of genus Staphylococcus. The evolutionary history was inferred using the neighbor-joining method. The percentages $(\geq 50 \%)$ of replicate trees in which the associated taxa clustered together in the bootstrap test (1000 replicates) are shown. The evolutionary distances were computed using the Maximum Composite Likelihood method and are in the units of the number of base substitutions per site 


\section{Greenhouse experiment}

\section{Effect of inoculation of Staphylococcus strains on maize growth}

A significant (Fisher's LSD; $P \leq 0.05$ ) increase in root and shoot length was observed after inoculation of maize plants with Staphylococcus strains STN-1, STN-5, and mixed inoculum (Fig. 2). Although the length of plant roots and shoots was significantly reduced up to $200 \mathrm{mM}$ of $\mathrm{NaCl}$ stress, the growth-promoting effect of strains STN-1, STN-5, and mixed inoculum was evident. The maximum length of root and shoot was measured in plants inoculated with mixed inoculum, whereby the root and shoot length of plants inoculated with mixed inoculum were $62.75 \%$ and $40.21 \%$ greater than noninoculated ones at maximum salt stress $(200 \mathrm{mM})$, respectively. Similarly, strains STN-1, STN-5, and mixed inoculation significantly promoted the maize biomass, which was evident from root and shoot fresh and dry weight data. An increasing salt concentration negatively affected the plant biomass, but strains STN-1, STN-5, and mixed inoculation seemed to tolerate the salt stress followed by a beneficial effect on plant biomass. At $200 \mathrm{mM}$ salt concentration, the mixed inoculation produced maximum plant fresh and dry weights, where the fresh weight was found $81.90 \%$ and $33.22 \%$ and dry weight was measured $65.50 \%$ and $61.41 \%$ higher than the noninoculated control plants, respectively. Interestingly, Staphylococcus strain STN-14 failed to exert a positive inoculation effect on maize growth in all the growth parameters studied under salt stress conditions.

\section{Effect of inoculation of Staphylococcus strains on maize physiology}

A significant increase in lipid peroxidation was estimated in maize plants with gradual enhancement in salt concentration up to $200 \mathrm{mM}$. It could be easily concluded from the data that inoculation of Staphylococcus strains STN-1, STN-5, and mixed inoculum significantly decreased the lipid peroxidation in maize plants in order to relieve cells from oxidative damage. At $200 \mathrm{mM}$ salt stress, the lipid peroxidation measured in terms of malondialdehyde (MDA) was $62.29 \%, 42.46 \%$, and 49.29\% less in plants inoculated with Staphylococcus strains STN-1, STN-5, and mixed inoculum, respectively. Interestingly, there was no gradual increase in $\mathrm{H}_{2} \mathrm{O}_{2}$ and proline contents of maize plants with increasing salt stress; however, inoculation of maize plants with strains STN-1, SNT-5, and mixed inoculum significantly decreased $\mathrm{H}_{2} \mathrm{O}_{2}$ and proline contents at all salt concentrations. At maximum salt concentration $(200 \mathrm{mM})$, the $\mathrm{H}_{2} \mathrm{O}_{2}$ contents of STN-1, STN-5, and mixed culture were found to be $42.43 \%, 43.86 \%$, and $47.38 \%$ less than non-inoculated plants, whereas the proline contents were estimated $\left(2.110,2.077\right.$, and $2.060 \mathrm{mg} \mathrm{g}^{-1} \mathrm{DW}$, respectively) to be statistically at par with control plants. On the other hand, the activity of cellular antioxidant enzymes like catalase (CAT) and peroxidase (POD) was significantly boosted with gradual increase in salt concentration. The maximum CAT and POD activity was measured in plants inoculated with mixed inoculum, which was $53.76 \%$ and $6.38 \%$ higher as compared to non-inoculated ones at $200 \mathrm{mM} \mathrm{NaCl}$ concentration. Similarly, the CAT and POD activities of plants inoculated with strains STN-1 and STN-5 were found significantly higher than non-treated plants (Fig. 3). In addition, a significant decrease in total phenolic contents was calculated with increasing salt stress treatment. Among the inoculation treatments, the plants inoculated with mixed inoculum showed maximum phenolic contents $\left(36.770 \mathrm{mg} \mathrm{g}^{-1} \mathrm{FW}\right)$ followed by plants inoculated with strain STN-1 (35.680 $\left.\mathrm{mg} \mathrm{g}^{-1} \mathrm{FW}\right)$ and STN-5 (31.773 $\mathrm{mg} \mathrm{g}^{-1} \mathrm{FW}$ ) as compared to non-treated plants $\left(19.960 \mathrm{mg} \mathrm{g}^{-1} \mathrm{FW}\right)$ at $100 \mathrm{mM}$ salt stress. The inoculation effect of strain STN-14 was found non-significant in terms of reducing the cellular oxidative damage and boosting the antioxidant enzymes in plants grown under induced salt stress conditions.

\section{Effect of inoculation of Staphylococcus strains on maize nutrient uptake and ion regulation}

It was evident from the data that the inoculation of maize plants with Staphylococcus strains STN-1, STN-5, and mixed inoculum significantly enhanced the $\mathrm{N}$ and $\mathrm{P}$ uptake from soil (Fig. 4). At $200 \mathrm{mM}$ salt stress, the maximum $\mathrm{N}$ contents were found in plants inoculated with strain STN-5 and mixed inoculum, which were $35.04 \%$ and $34.85 \%$ high than non-treated control plants, respectively. The P contents were maximum in maize plants inoculated with strain STN-5, which were $42.13 \%$ high than non-inoculated plants at $200 \mathrm{mM}$ salt stress. Strain STN-1 inoculation also significantly promoted the nutrient uptake at all salt concentrations. A 36.00\%, 38.29\%, and $45.21 \%$ decrease in $\mathrm{Na}^{+}$ion contents was estimated in plants inoculated with strain STN-1, STN-5, and mixed inoculum, respectively, at $200 \mathrm{mM}$ salt concentration. The uptake of $\mathrm{K}^{+}$ and $\mathrm{Ca}^{+2}$ ions was significantly promoted as result of the inoculation of strain STN-1, STN-5, and mixed inoculum under induced salinity conditions. Moreover, the uptake of $\mathrm{K}^{+}$ and $\mathrm{Ca}^{+2}$ ions was significantly reduced with increased salinity stress. At $200 \mathrm{mM}$ salt stress, the maximum $\mathrm{K}^{+}$and $\mathrm{Ca}^{+2}$ ion uptake was found in plants inoculated with mixed inoculum, which was $33.19 \%$ and $80.36 \%$ higher, respectively. Similarly, the $\mathrm{K}^{+} / \mathrm{Na}^{+}$ratio was estimated significantly higher in mixed inoculum-treated plants followed by plants inoculated with strains STN-1 and STN-5 at 200 mM salt stress, while $\mathrm{Ca}^{+2} / \mathrm{Na}^{+}$ratio was found statistically higher in plants inoculated with strains STN-1, STN-5, and mixed inoculum. Again, the inoculation of strain STN-14 failed to trigger nutrient 

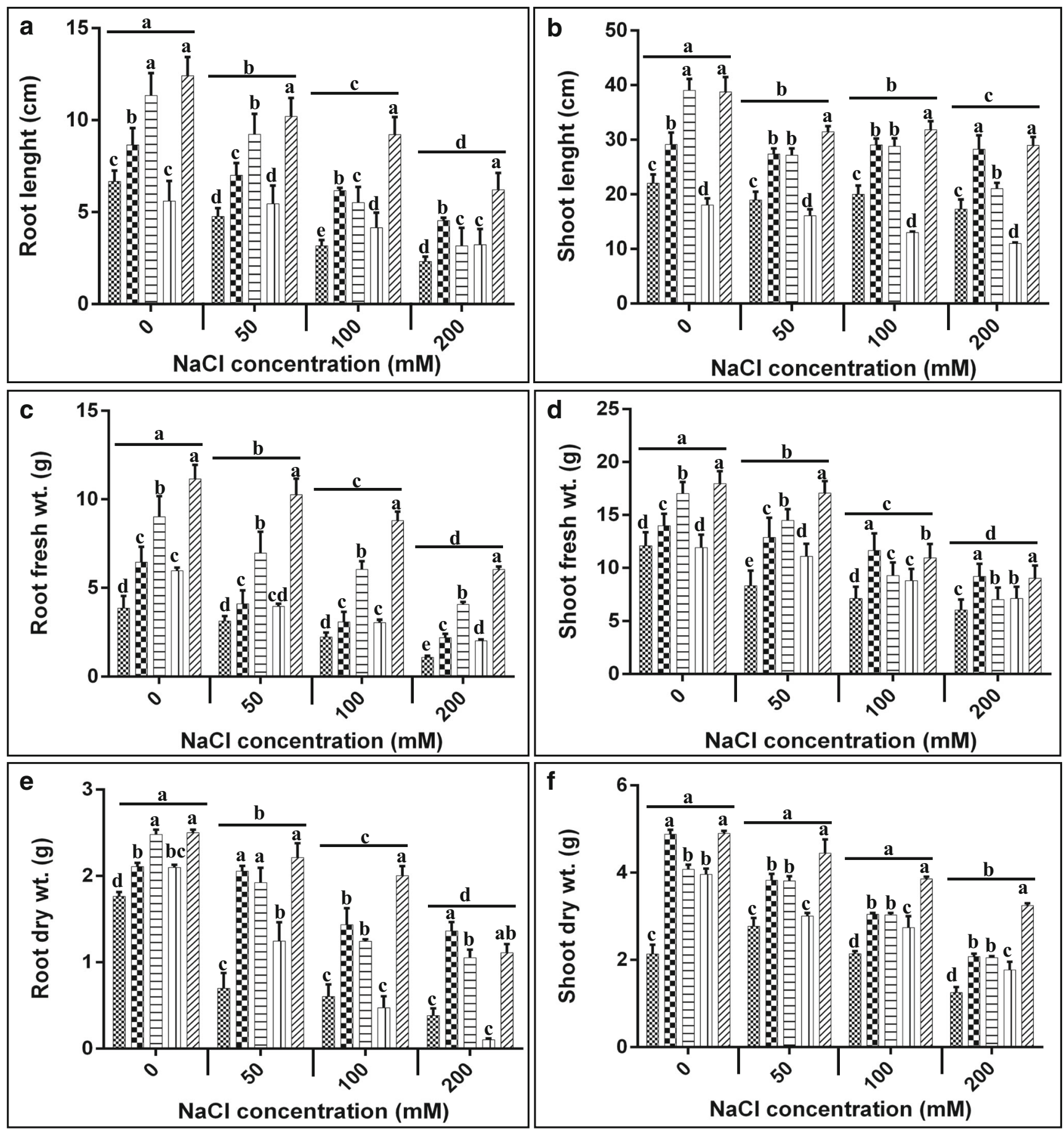

\section{\% Control W STN-1}

Fig. 2 Effect of salt-tolerant Staphylococcus strains on growth parameters of maize under induced salinity stress. The data was analyzed by two-way analysis of variance (Fisher's LSD; $P \leq 0.05$ ). Different lowercase letters on bars represent the significance among inoculated and non-inoculated treatment means $(n=3)$ and the letters on horizontal lines corresponds to the significance among induced salinity levels

팔 Non-inoculated plants.

m= Plants inoculated with Staphylococcus strain STN-1.

Е= Plants inoculated with Staphylococcus strain STN-5.

ImII= Plants inoculated with Staphylococcus strain STN-14.

एשa: $=$ Plants inoculated with mixed inoculum. 

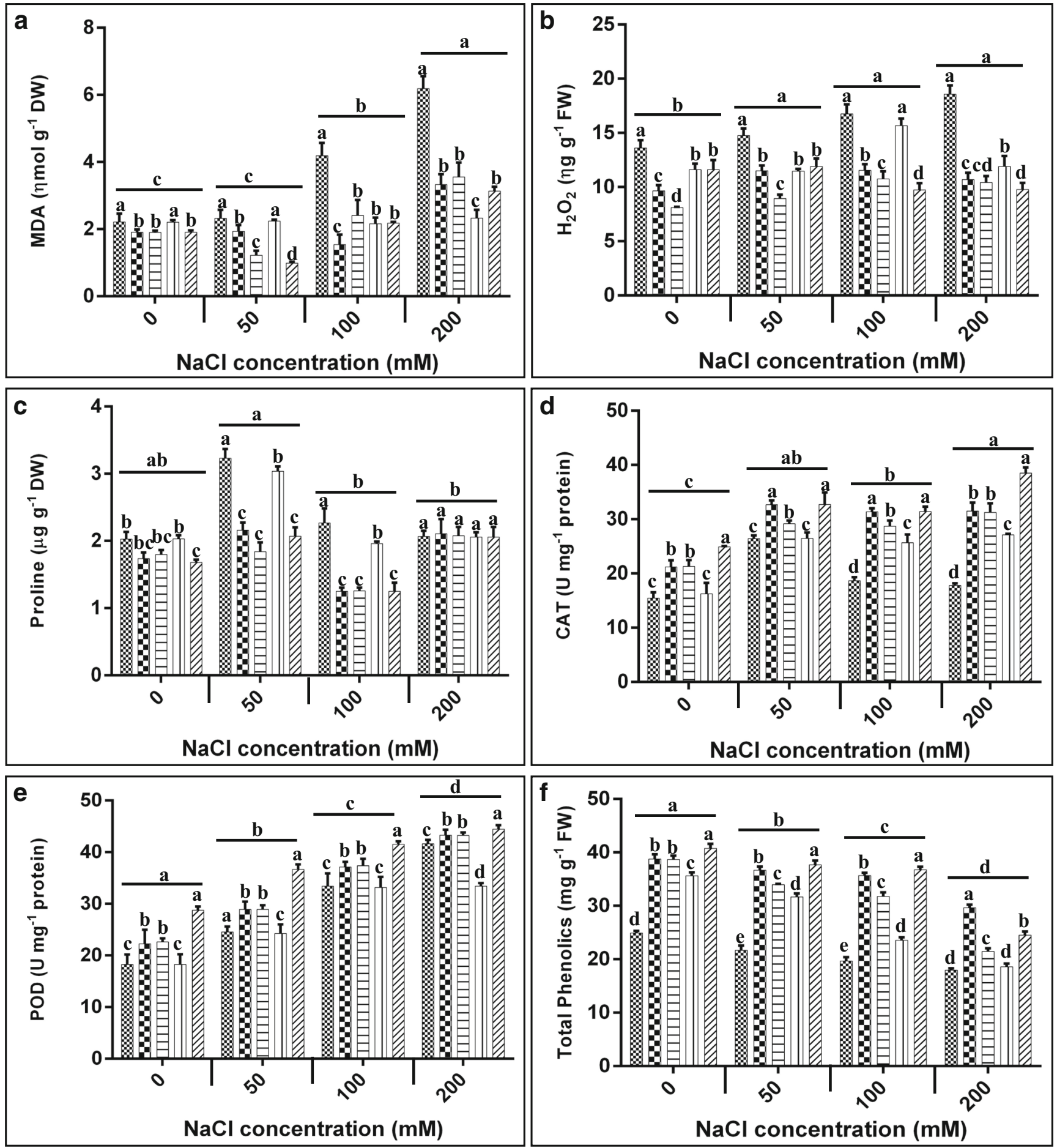

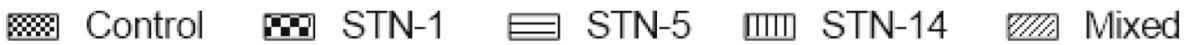

Fig. 3 Effect of salt-tolerant Staphylococcus strains on cellular antioxidants and reactive oxygen species under induced salt stress. The data was analyzed by two-way analysis of variance (Fisher's LSD; $P \leq 0.05$ ). Different lowercase letters on bars represent the significance among inoculated and noninoculated treatment means $(n=3)$ and the letters on horizontal lines correspond to the significance among induced salinity levels $\approx=$ Non-inoculated plants.

mants inoculated with Staphylococcus strain STN-1.

Е= Plants inoculated with Staphylococcus strain STN-5.

$\mathrm{ImIm}=$ Plants inoculated with Staphylococcus strain STN-14.

एकe $=$ Plants inoculated with mixed inoculum. 
uptake and to establish ionic balance in maize plants under induced salinity conditions (Fig. 4).

\section{Discussion}

Soil salinity is a major agricultural problem frequently prevailing in arid and semiarid soils of Pakistan (Qureshi et al. 2008). Although salts are required by plants in certain amounts to maintain normal functions, their high concentration in the soil inhibits plant metabolic functions except in halophytes. Nowadays, salt-tolerant bacteria, especially the PGPR, are being extensively investigated as supplements to chemical fertilizers to support plant growth and induce salinity tolerance (Akram et al. 2016; Shahid et al. 2018). In the present study, three Staphylococcus strains were physiologically characterized as phytobeneficial and salt tolerant under in vitro conditions and they promoted maize growth by mitigating cellular oxidative damage and maintaining ion regulation.

The Staphylococcus strains were isolated from kallar grass, which is a well-known halophytic plant and wildly found on saline areas (Ola et al. 2012). The taxonomic explanation of the three strains was based on 16S rRNA gene analysis, which suggested the molecular identity as Staphylococcus (MH152329, MH152330, and MH152331) (Table 2). Furthermore, the phylogeny of the Staphylococcus strains STN-1, STN-5, and STN-14, studied by neighbor-joining phylogenetic tree, with the type strains of the same genus also confirmed the molecular identity. Many Staphylococcus species have been identified as commensal pathogens of animals (Nemeghaire et al. 2014) and plants (Prithiviraj et al. 2005); however, their ecological existance in terms of salt-tolerant species (Khan et al. 2015; Akram et al. 2016) and phytobeneficial agents (Yildrim et al. 2008; Akram et al. 2016) is well reported. Akram et al. (2016) reported the increased growth of maize plants in response to the inoculation of Staphylococcus sciuri SAT-17 under induced salinity stress. Rhizosphere acidosis is necessary to release the bound soil phosphates from cations $\left(\mathrm{Ca}^{+2}, \mathrm{Al}^{+2}\right.$, and $\left.\mathrm{Fe}^{+2}\right)$. The in vitro measurement of this soil acidification is directly related to solubilization of tricalcium phosphate in culture medium. Substantial phosphate solubilization ability was measured in Staphylococcus strains, which means that the strains might have organic acid synthesis ability. The in vitro phosphate solubilization ability of Staphylococcus strains STN-1, STN5 , and STN-14 was comparable with those reported previously (Akram et al. 2016; Alibrandi et al. 2018). The strains STN1 , STN-5, and STN-14 exhibited substantial in vitro IAA synthesizing capacity both in the presence as well as in the absence of tryptophan (Trp) representing that both Trpdependent and Trp-independent pathways were active in Staphylococcus strains. In addition, the Staphylococcus strains were also found to show ACC deaminase activity, which is evident from the amount of $\alpha$-ketobutyrate produced in the culture medium. Bacterial ACC deaminase activity synthesis is a characteristic with utmost importance in stress tolerance induction in plants when bacteria is in association with roots or aerial parts due to cleavage of ACC into $\alpha$-ketobutyrate and ammonia in plant cells by the activity of this enzyme (Glick 2014; Mahmood et al. 2017). Moreover, the IAA is an important signaling molecule involved in root cell proliferation and elongation even in very small concentrations (Glick 2014; Liu et al. 2018). When bacteria associate with plant roots, both bacterially produced IAA and plant IAA trigger the transcription of ACC synthase followed by synthesis of substantial amounts of ACC. Some of the ACC will ultimately be exuded from the roots and converted to ammonia and $\alpha$-ketobutyrate before being converted to ethylene in plants. Thus, both IAA and ACC deaminase synthesis activities of PGPR are directly involved in plant growth and stress alleviation (Glick 2014). Before direct inoculation onto maize plants, pathogenicity testing of Staphylococcus strains STN-1, STN-5, and STN14 was investigated and the strains were found non-pathogenic.

It has been documented that salt-tolerant PGPR inoculation in salt-affected soils has ultimately resulted in an increased plant biomass in addition to alleviation of deleterious effects of salt stress (Kim et al. 2014; Akram et al. 2016; Shahid et al. 2018). Evidences are also available for enhancement of nonhalotolerant plant growth by the inoculation of PGPR isolated from the rhizosphere of halophytes (Etesami and Beattie 2018). Results revealed that the inoculation with Staphylococcus strains STN-1, STN-5, or mixed inocula significantly increased the maize growth up to $200 \mathrm{mM} \mathrm{NaCl}$ concentration. This growth-stimulating effect might be due to better soil phosphate mobilization, IAA synthesis, and ACC deaminase ability of these strains as compared to noninoculated plants. Under stress conditions, ACC deaminase becomes vital due to regulation of plant cell ethylene levels. The proposed model (Glick 2014) states that IAA stimulates the synthesis of ACC in plant cells, which is secreted by plant roots and consumed by associated bacteria as nitrogen source. Hence, more secretion of ACC by plant roots leads to less cellular ethylene levels. Moreover, the strain STN-14 failed to promote maize growth under saline conditions possibly due to poor colonization and adaptation with semi-natural environment of plant roots after inoculation. The phytohormone IAA is reported to stimulate the formation of root hairs followed by the intense colonization of plant with PGPR strains and more access of roots to nutrients and water (Couillerot et al. 2011; Shahid et al. 2015). Moreover, decrease in maize length and biomass with increasing salt stress may be attributed to limited water uptake due to the ion osmotic potential, reduced photosynthetic activity, less nutrient uptake, and disturbance in many other metabolic functions (Kumar et al. 2005). The maximum plant growth-promoting potential of mixed inoculation may be attributed to cumulative effect of strains STN-1 

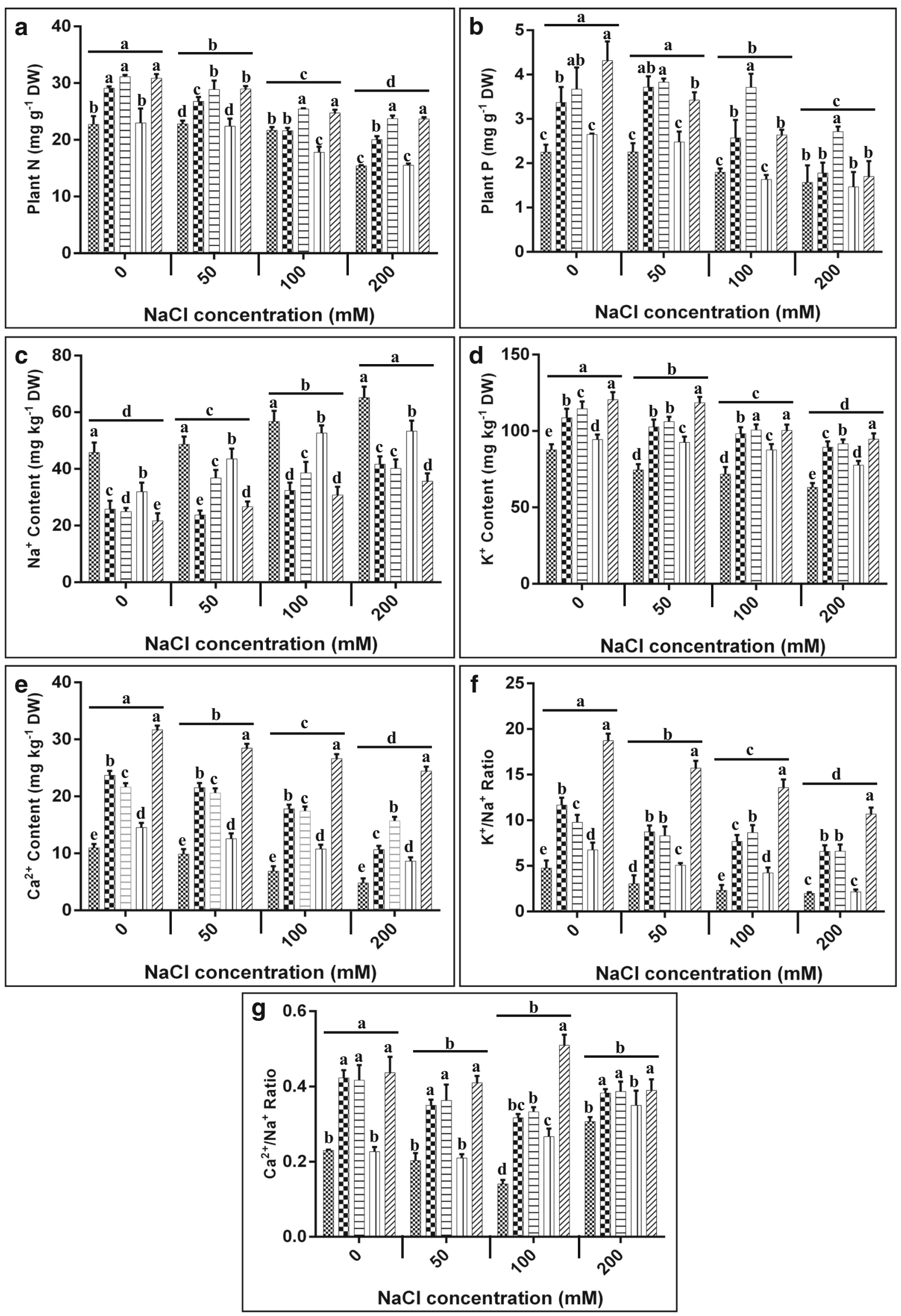

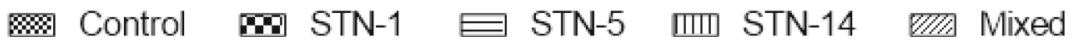


Fig. 4 Effect of salt-tolerant Staphylococcus strains on nutrient uptake and ion regulation under induced salt stress. The data was analyzed by two-way analysis of variance (Fisher's LSD; $P \leq 0.05$ ). Different lowercase letters on bars represent the significance among inoculated and noninoculated treatment means $(n=3)$ and the letters on horizontal lines corresponds to the significance among induced salinity levels

\%:F= Non-inoculated plants.

= Plants inoculated with Staphylococcus strain STN-1.

E= Plants inoculated with Staphylococcus strain STN-5.

$\mathrm{IIT}=$ Plants inoculated with Staphylococcus strain STN-14.

m= Plants inoculated with mixed inoculum.

and STN-5 (Fig. 2). The modulation of ethylene stress due to production of ACC deaminase by Staphylococcus strains might also have added to the growth stimulatory effects in inoculated maize plants (Glick 2014; Kim et al. 2014). Shahid et al. (2018) concluded that Planomicrobium sp. MSSA-10 with PGPR characteristics promoted the growth of pea plants under induced salinity stress. Moreover, Ahmad et al. (2014) reported that the combined application of PGPR, biogas slurry, and nitrogen boosted the growth of maize. Inoculation with Erwinia persicinus strain RA2 significantly increased biomass of tomato plants under salinity conditions (Cha-Um and Kirdmanee 2009).

In non-treated plants, the MDA and $\mathrm{H}_{2} \mathrm{O}_{2}$ content were elevated with the increasing levels of salt stress. This was the indication that the plants cells were in oxidative injury (Nasraoui-Hajaji et al. 2012). This condition not only affects cellular metabolic activity but also nutrient and water uptake from soil. The significant decrease in lipid oxidation of membranes and in $\mathrm{H}_{2} \mathrm{O}_{2}$ content, and the increase in cellular antioxidant enzyme content (CAT and POD) in plants inoculated with Staphylococcus strains STN-1, STN-5, and mixed inoculum might be attributed to the complex signaling pathways triggered by bacterial inoculation (Fig. 3). It has been already established that PGPR induced stress tolerance in plants by triggering the cellular antioxidant levels (Younesi and Moradi 2014; Shahid et al. 2018). Proline is a very important osmolyte involved in osmoregulation and stabilization of many other macromolecules (Curá et al. 2017). In the present study, inoculated plants showed reduced proline contents, which could be attributed to the fact that the inoculation of maize plants with strains STN-1, STN-5, and mixed inoculum alleviated the plants from stress conditions. The synthesis of elevated levels of hydrogen peroxide $\left(\mathrm{H}_{2} \mathrm{O}_{2}\right)$, superoxide $\left(\mathrm{O}_{2}{ }^{-}\right)$, and/ or hydroxyl $\left(\mathrm{OH}^{-}\right)$radicals are the direct signals of oxidative stress (Waszczak et al. 2018). Conversely, plant antioxidant defense mechanism, composing of enzymatic and nonenzymatic molecules, ensure the defense against the adverse effects of ROS (Sun et al. 2018). Another possible mechanism of salt stress alleviation in plants is the bacterial exopolysaccharides synthesis, which restricts the uptake of $\mathrm{Na}^{+}$by roots (Ilangumaran and Smith 2017) and regulate the tissue-specific sodium transporter HKT1 (Zhang et al. 2008).
Sahoo et al. (2014) reported that the inoculation of rice plants with Azotobacter vinellandii (SRIAz3) resulted in an increased rice biomass. The inoculation of Staphylococcus strains STN1, STN-5, and mixed inoculum increased the total phenolic contents in maize plants and this phenomenon might be attributed to better utilization of cellar antioxidative repair mechanisms by plants as compared to non-treated ones (Akram et al. 2016). The maximum antioxidant levels in plants treated with mixed inoculum might be due to the synergistic effect of strains STN-1 and STN-5.

It was found that the uptake of $\mathrm{N}$ and $\mathrm{P}$ in maize showed a decreasing trend with increasing salt stress, probably due to increased $\mathrm{Na}^{+}$and $\mathrm{Cl}^{-}$ions uptake (Fig. 4). It is well established that under salt stress, the uptake of $\mathrm{K}^{+}$and $\mathrm{Ca}^{+2}$ is reduced due to the antagonistic effect of $\mathrm{Na}^{+}$and $\mathrm{K}^{+}$ (Rahneshan et al. 2018). Increased uptake of $\mathrm{N}, \mathrm{P}, \mathrm{K}^{+}$, and $\mathrm{Ca}^{+2}$ as a result of the inoculation with Staphylococcus strains STN-1, STN-5, and mixed inoculum may be attributed to the plant growth-promoting and nutrient mobilization potential of the strains, root proliferation due to IAA production, and low $\mathrm{Na}^{+}$uptake. The $\mathrm{K}^{+} / \mathrm{Na}^{+}$and $\mathrm{Ca}^{2+} / \mathrm{Na}^{+}$ratios were also found comparatively higher in inoculated plants. The enhanced nutrient uptake might be due to the better root growth due to PGPR inoculation (Shahid et al. 2012). However, the mechanisms underlying bacterially induced ion regulation and nutrient translocation from soil to plant shoot are not completely understood. Furthermore, IAA production might have stimulated the uptake of $\mathrm{K}^{+}$and $\mathrm{Ca}^{+2}$ with subsequent restriction in the uptake of $\mathrm{Na}^{+}$, and this relation between ion regulation and nutrient uptake is presented by Forni et al. (2017).

\section{Conclusion}

Three strains STN-1, STN-5, and STN-14 were taxonomically identified as Staphylococcus spp. and physiologically characterized as salt-tolerant PGPR strains. Inoculation of maize plants with Staphylococcus strains STN-1, STN-5, and mixed inoculum significantly promoted plant growth and alleviated maize plants from oxidative damage by decreasing the levels of reactive oxygen species due to enhanced production of enzymatic and non-enzymatic antioxidants. It was found that salt stress alleviation after the inoculation with STN-1, STN-5, and mixed inoculum was also the result of better nutrient acquisition and regulation of ionic balance in plant cells. The study concluded that Staphylococcus strains STN-1 and STN-5 are potent salt-tolerant PGPR, which can be used as mixed inoculum to boost maize growth under saline environment.

Funding This research work was funded by GCUF-RSP research grant (project no. 38-B\&B-15) entitled "Development of salt-tolerant biofertilizer for saline agriculture in Pakistan." 


\section{Compliance with ethical standards}

Conflict of interest The authors declare that they have no conflict of interest.

Ethical approval This article does not contain any studies with human participants or animals performed by any of the authors.

Informed consent Informed consent was obtained from all individual participants included in the study.

\section{References}

Aebi H (1984) Catalase in vitro. Methods Enzymol Elsevier; p 121-126

Ahmad M, Zahir ZA, Jamil M, Nazli F, Latif M, Akhtar M (2014) Integrated use of plant growth promoting rhizobacteria, biogas slurry and chemical nitrogen for sustainable production of maize under salt-affected conditions. Pak J Bot 46(1):375-382

Akram MS, Shahid M, Tariq M, Azeem M, Javed MT, Saleem S, Riaz S (2016) Deciphering Staphylococcus sciuri SAT-17 mediated antioxidative defense mechanisms and growth modulations in salt stressed maize (Zea mays L.). Front Microbiol 7:867

Alibrandi P, Cardinale M, Rahman MM, Strati F, Ciná P, de Viana ML, Giamminola EM, Gallo G, Schnell S, De Filippo C (2018) The seed endosphere of Anadenanthera colubrina is inhabited by a complex microbiota, including Methylobacterium spp. and Staphylococcus spp. with potential plant-growth promoting activities. Plant Soil 422(1-2):81-99

Arnon D, Hoagland D (1940) Crop production in artificial culture solutions and in soils with special reference to factors influencing yields and absorption of inorganic nutrients. Soil Sci 50:463-485

Babalola OO (2010) Beneficial bacteria of agricultural importance. Biotechnol Lett 32(11):1559-1570

Bates L, Waldren R, Teare I (1973) Rapid determination of free proline for water-stress studies. Plant Soil 39(1):205-207

Bradford MM (1976) A rapid and sensative method for the quantitation of microgram quantities of protein utilizing the principle of proteindye binding. Ann Biochem 72:248-254

Cha-Um S, Kirdmanee C (2009) Effect of salt stress on proline accumulation, photosynthetic ability and growth characters in two maize cultivars. Pak J Bot 41(1):87-98

Chance B, Maehly A (1955) Assay of catalases and peroxidases. Methods Enzymol 2:764-775

Cheng Z, Woody OZ, McConkey BJ, Glick BR (2012) Combined effects of the plant growth-promoting bacterium Pseudomonas putida UW4 and salinity stress on the Brassica napus proteome. Appl Soil Ecol 61:255-263

Compant S, Duffy B, Nowak J, Clément C, Barka EA (2005) Use of plant growth-promoting bacteria for biocontrol of plant diseases: principles, mechanisms of action, and future prospects. Appl Environ Microbiol 71(9):4951-4959

Couillerot O, Combes-Meynet E, Pothier JF, Bellvert F, Challita E, Poirier M-A, Rohr R, Comte G, Moënne-Loccoz Y, PrigentCombaret C (2011) The role of the antimicrobial compound 2, 4diacetylphloroglucinol in the impact of biocontrol Pseudomonas fluorescens F113 on Azospirillum brasilense phytostimulators. Microbiol 157(6):1694-1705

Curá JA, Franz DR, Filosofía JE, Balestrasse KB, Burgueño LE (2017) Inoculation with Azospirillum sp. and Herbaspirillum sp. bacteria increases the tolerance of maize to drought stress. Microorganisms $5(3): 41$

Dimkpa C, Weinand T, Asch F (2009) Plant-rhizobacteria interactions alleviate abiotic stress conditions. Plant Cell Environ 32(12):16821694

Dobbelaere S, Vanderleyden J, Okon Y (2003) Plant growth-promoting effects of diazotrophs in the rhizosphere. Crit Rev Plant Sci 22(2): $107-149$

Etesami H, Beattie GA (2018) Mining halophytes for plant growthpromoting halotolerant bacteria to enhance the salinity tolerance of non-halophytic crops. Front Microbiol 9:148

Forni C, Duca D, Glick BR (2017) Mechanisms of plant response to salt and drought stress and their alteration by rhizobacteria. Plant Soil 410(1-2):335-356

Gerhardt P, Murray RGE, Costilow RN, Nester EW, Wood WA, Krieg NR, Phillips GB (1981) Manual of methods for general bacteriology. American Society for Microbiology, Washington, DC ISBN 0914826-30-1

Glick BR (2014) Bacteria with ACC deaminase can promote plant growth and help to feed the world. Microbiol Res 169(1):30-39

Gordon SA, Weber RP (1951) Colorimetric estimation of indoleacetic acid. Plant Physiol 26(1):192-195

Hamdia MAE-S, Shaddad M, Doaa MM (2004) Mechanisms of salt tolerance and interactive effects of Azospirillum brasilense inoculation on maize cultivars grown under salt stress conditions. Plant Growth Regul 44(2):165-174

Harrigan WF, McCance ME (1990) Laboratory methods and food and dairy microbiology. Academic Press, London

Heath RL, Packer L (1968) Photoperoxidation in isolated chloroplasts: I. Kinetics and stoichiometry of fatty acid peroxidation. Arch Biochem Biophys 125(1):189-198

Heydarian Z, Yu M, Gruber M, Glick BR, Zhou R, Hegedus DD (2016) Inoculation of soil with plant growth promoting bacteria producing 1-aminocyclopropane-1-carboxylate deaminase or expression of the corresponding acdS gene in transgenic plants increases salinity tolerance in Camelina sativa. Front Microbiol 7:1966

Ilangumaran G, Smith DL (2017) Plant growth promoting rhizobacteria in amelioration of salinity stress: a systems biology perspective. Front Plant Sci 8:1768

Jana S, Choudhuri MA (1982) Glycolate metabolism of three submersed aquatic angiosperms during ageing. Aquat Bot 12:345-354

Julkunen-Tiitto R (1985) Phenolic constituents in the leaves of northern willows: methods for the analysis of certain phenolics. J Agric Food Chem 33(2):213-217

Kashyap AS, Pandey VK, Manzar N, Kannojia P, Singh UB, Sharma P (2017) Role of plant growth-promoting rhizobacteria for improving crop productivity in sustainable agriculture. Plant-Microbe Interactions in Agro-Ecological Perspectives Springer; pp 673-693

Khan MU, Sessitsch A, Harris M, Fatima K, Imran A, Arslan M, Shabir G, Khan QM, Afzal M (2015) Cr-resistant rhizo- and endophytic bacteria associated with Prosopis juliflora and their potential as phytoremediation enhancing agents in metal-degraded soils. Front Plant Sci 5:755

Kim K, Jang Y-J, Lee S-M, Oh B-T, Chae J-C, Lee K-J (2014) Alleviation of salt stress by Enterobacter sp. EJ01 in tomato and Arabidopsis is accompanied by up-regulation of conserved salinity responsive factors in plants. Mol Cell 37(2):109

Kumar A, Bahadur I, Maurya B, Raghuwanshi R, Meena V, Singh D, Dixit J (2015) Does a plant growth promoting rhizobacteria enhance agricultural sustainability. J Pure Appl Microbiol 9(1):715-724

Kumar R, Goyal V, Kuhad M (2005) Influence of fertility-salinity interactions on growth, water status and yield of Indian mustard (Brassica juncea). Indian J Plant Physiol 10(2):139

Liu M, Chen Y, Chen Y, Shin JH, Mila I, Audran C, Zouine M, Pirrello J, Bouzayen M (2018) The tomato ethylene response factor Sl-ERF. 
B3 integrates ethylene and auxin signaling via direct regulation of Sl-aux/IAA 27. New Phytol 9(2):631-640

Mahmood F, Shahid M, Hussain S, Shahzad T, Tahir M, Ijaz M, Hussain A, Mahmood K, Imran M, Babar SAK (2017) Potential plant growth-promoting strain Bacillus sp. SR-2-1/1 decolorized azo dyes through NADH-ubiquinone: oxidoreductase activity. Bioresour Technol 235:176-184

Maniatis T, Fritsch EF, Sambrook J (1982) Molecular cloning: a laboratory manual, vol 545. Cold Spring Harbor Laboratory, Cold Spring Harbor, NY

Mayak S, Tirosh T, Glick BR (2004) Plant growth-promoting bacteria confer resistance in tomato plants to salt stress. Plant Physiol Biochem 42(6):565-572

Meena VS, Meena SK, Verma JP, Kumar A, Aeron A, Mishra PK, Bisht JK, Pattanayak A, Naveed M, Dotaniya M (2017) Plant beneficial rhizospheric microorganism (PBRM) strategies to improve nutrients use efficiency: a review. Ecol Eng 107:8-32

Nasraoui-Hajaji A, Gouia H, Carrayol E, Haouari-Chaffei C (2012) Ammonium alleviates redox state in Solanum seedlings under cadmium stress conditions. J Environ Anal Toxicol 2:116-120

Nemeghaire S, Argudín MA, Feßler AT, Hauschild T, Schwarz S, Butaye P (2014) The ecological importance of the Staphylococcus sciuri species group as a reservoir for resistance and virulence genes. Vet Microbiol 171(3-4):342-356

Ola HAE, Reham EF, Eisa S, Habib S (2012) Morpho-anatomical changes in salt stressed kallar grass (Leptochloa fusca L. Kunth). Res J Agric Biol Sci 8(2):158-166

Panda SK, Baluška F, Matsumoto H (2009) Aluminum stress signaling in plants. Plant Signal Behav 4(7):592-597

Penrose DM, Glick BR (2003) Methods for isolating and characterizing ACC deaminase-containing plant growth-promoting rhizobacteria. Physiol Plant 118:10-15

Pikovskaya R (1948) Mobilization of phosphorus in soil in connection with vital activity of some microbial species. Mikrobiologiya 17: 362-370

Prithiviraj B, Bais HP, Jha AK, Vivanco JM (2005) Staphylococcus aureus pathogenicity on Arabidopsis thaliana is mediated either by a direct effect of salicylic acid on the pathogen or by SA-dependent, NPR1-independent host responses. Plant J 42(3):417-432

Qureshi AS, McCornick PG, Qadir M, Aslam Z (2008) Managing salinity and waterlogging in the Indus Basin of Pakistan. Agric Water Manag 95(1):1-10

Rahneshan Z, Nasibi F, Moghadam AA (2018) Effects of salinity stress on some growth, physiological, biochemical parameters and nutrients in two pistachio (Pistacia vera L.) rootstocks. J Plant Interact 13(1):73-82

Roohi A, Ahmed I, Iqbal M, Jamil M (2012) Preliminary isolation and characterization of halotolerant and halophilic bacteria from salt mines of Karak, Pakistan. Pak J Bot 44(SI 1):365-370

Ryan J, Estefan G, Rashid, A (2007) Soil and plant analysis laboratory manual. ICARDA

Sahoo RK, Ansari MW, Pradhan M, Dangar TK, Mohanty S, Tuteja N (2014) A novel Azotobacter vinellandii (SRI Az 3) functions in salinity stress tolerance in rice. Plant Signal Behav 9(7):511-523

Shahbaz M, Ashraf M (2013) Improving salinity tolerance in cereals. Crit Rev Plant Sci 32(4):237-249

Shahid M, Akram MS, Khan MA, Zubair M, Shah SM, Ismail M, Not Shabir G, Basheer S, Aslam K, Tariq M (2018) A phytobeneficial strain Planomicrobium sp. MSSA-10 triggered oxidative stress responsive mechanisms and regulated the growth of pea plants under induced saline environment. J Appl Microbiol 124(6):1566-1579

Shahid M, Hameed S, Imran A, Ali S, van Elsas JD (2012) Root colonization and growth promotion of sunflower (Helianthus annuus L.) by phosphate solubilizing Enterobacter sp. Fs-11. World J Microbiol Biotechnol 28(8):2749-2758

Shahid M, Hameed S, Tariq M, Zafar M, Ali A, Ahmad N (2015) Characterization of mineral phosphate-solubilizing bacteria for enhanced sunflower growth and yield-attributing traits. Ann Microbiol 65(3):1525-1536

Shahid M, Hussain B, Riaz D, Khurshid M, Ismail M, Tariq M (2017) Identification and partial characterization of potential probiotic lactic acid bacteria in freshwater Labeo rohita and Cirrhinus mrigala. Aquac Res 48(4):1688-1698

Shrivastava P, Kumar R (2015) Soil salinity: a serious environmental issue and plant growth promoting bacteria as one of the tools for its alleviation. Saudi J Biol Sci 22(2):123-131

Shukla PS, Agarwal PK, Jha B (2012) Improved salinity tolerance of Arachis hypogaea (L.) by the interaction of halotolerant plantgrowth-promoting rhizobacteria. J Plant Growth Regul 31(2):195206

Somasegaran P, Hoben HJ (1994) Handbook for rhizobia: methods in legume-rhizobium technology. Springer Science \& Business Media

Spaepen S, Vanderleyden J (2011) Auxin and plant-microbe interactions. Cold Spring Harb Perspect Biol 3(4):a001438

Steel R, Torrie J, Dickey DA (1997) Principles and procedures of statistics: a biometrical approach. McGraw-Hill

Sun H, Mu B, Song Z, Ma Z, Mu T (2018) The in vitro antioxidant activity and inhibition of intracellular reactive oxygen species of sweet potato leaf polyphenols. Oxidative Med Cell Longev 2018:11

Waszczak C, Carmody M, Kangasjärvi J (2018) Reactive oxygen species in plant signaling. Annu Rev Plant Biol 69:209-236

Weisburg WG, Barns SM, Pelletier DA, Lane DJ (1991) 16S ribosomal DNA amplification for phylogenetic study. J Bacteriol 173(2):697703

Wolf B (1982) A comprehensive system of leaf analyses and its use for diagnosing crop nutrient status. Commun Soil Sci Plant Anal 13: 1035-1059. https://doi.org/10.1080/00103628209367332

Yildrim E, Donmez MF, Turan M (2008) Use of bioinoculants in ameliorative effects on radish plants under salinity stress. J Plant Nutr 31(12):2059-2074

Younesi O, Moradi A (2014) Effects of plant growth-promoting rhizobacterium (PGPR) and arbuscular mycorrhizal fungus (AMF) on antioxidant enzyme activities in salt-stressed bean (Phaseolus vulgaris L.). Agric 60(1):10-21

Zafar S, Ashraf MY, Anwar S, Ali Q, Noman A (2016) Yield enhancement in wheat by soil and foliar fertilization of $\mathrm{K}$ and $\mathrm{Zn}$ under saline environment. Soil Environ 35(1):46-55

Zhang H, Kim M-S, Sun Y, Dowd SE, Shi H, Paré PW (2008) Soil bacteria confer plant salt tolerance by tissue-specific regulation of the sodium transporter HKT1. Mol Plant-Microbe Interact 21(6): $737-744$

Publisher's note Springer Nature remains neutral with regard to jurisdictional claims in published maps and institutional affiliations. 